\title{
Textualidad digital y multialfabetización. Los contenidos digitales como material educativo
}

\section{Digital textuality and multiliteracy. Digital contents as resource in education}

\author{
AmANdo López VALERO*1 \\ amandolo@um.es \\ ISABEL Jerez MARtínez** \\ isabel.jerezmartinez@uclm.es \\ *Universidad de Murcia, España \\ **Universidad de Castilla-La Mancha, España
}

\section{Resumen:}

El objetivo de este artículo tiene que ver con la relación que se establece entre el mundo educativo, la cultura y los contenidos digitales. Desde estas líneas queremos incidir en el concepto de hipertexto como nueva realidad de acceso al conocimiento. Si bien el concepto ya había sido tratado a lo largo del Siglo XX, es en la época que nos trasciende cuando se ha convertido en un elemento importante y en el concepto en el cual se concentran las prácticas lectoras. Hay pues una nueva definición del comportamiento lector que transita desde lo secuencial a la navegación libre en la construcción del conocimiento.

Considerando que existen nuevas alfabetizaciones en forma de acceso a tecnología multimedia, hemos escogido el contenido digital que supone el videojuego. Las posibilidades del mismo son variadas y permiten a la persona acceder a valores, conocimientos desde una perspectiva

\begin{abstract}
:
The aim of this article concerns the relationship among education, culture, and digital materials. Through these lines we develop the concept of the hypertext, as a new reality to get access to knowledge. Although the concept got thorough attention in the past century, nowadays it is very important and crucial to understand new reading trends. There is a new way of reading which goes from sequences to free interaction with texts in the building of knowledge.

The new literacy related to multimedia technology that we have chosen is the video game. Its possibilities are multiple, allowing people to learn and appreciate values from an informal and formal (if we apply it to the classroom) perspective. Our selection is related to the products from the Ubisoft Company, specifically the Assassin's creed video game, because this company is going beyond entertainment
\end{abstract}

1 Dirección para correspondencia (correspondence address):

Amando López Valero. Dpto. de Didáctica de la Lengua y la Literatura. Facultad de Educación. Universidad de Murcia. Campus de Espinardo. 30100, Murcia (España). 
Textualidad digital y multialfabetización. Los contenidos digitales como material educativo

Amando López Valero e Isabel Jerez Martínez

tanto informal como formal (si lo trasladamos al aula). Nuestra elección tiene que ver con los materiales producidos por la compañía Ubisoft, concretamente, la saga Assassin's Creed, quien confiere a sus producciones complejas tramas que albergan transtextualidad e hipertextos. Se plantea un uso educativo de este recurso con el fin de mostrar que el acto lector se encuentra en pleno proceso de evolución y la necesidad de la adaptación a la denominada cultura digital.

\section{Palabras clave:}

Contenidos digitales; Educación; Cultura; Hipertexto; Videojuegos. and it is giving complex plots with transtextuality and hypertexts to their productions. We suggest an educative use of these resources to demonstrate that reading tendencies are changing and people have to adapt to these processes and to the new demands from digital culture.

\section{Key words:}

Digital materials; Education; Culture; Hypertext; Video Games.

\section{Résumé:}

L'objetif de cet article est la relation entre le monde éducatif, la culture et les contenus digitaux. Nous voulons remarquer le concept d'hypertexte comme une nouvelle réalité d'accès à la connaissance. Si bien le concept a déjà été étudié tout au long du XXème Siècle, c'est dans le moment actuel quand il est devenu un concept important dans lequel les pratiques de lecture se concentrent. Donc, nous trouvons aujourd'hui une nouvelle définition du comportement lecteur que va dès la séquence à la libre navigation dans la construction de la connaissance.

On a trié le contenu digital du video jeux parce que nous sommes sûrs qu'il y a de nouvelles alphabétisations d'accès au multimédia technologique. Leurs possibilités sont variées et nous permettent accéder aux valeurs et à la connaissance depuis une perspective tant informelle que formelle (dans la classe). Nous avons choisi la vidéo de jeux comme un contenu digital. Notre choix est relationné directement avec les matériaux produits par la compagnie Ubisoft, concrètement la saga Assassin's Creed, laquelle donne à ses productions des complexes trames avec beaucoup de transtextualité et d'hypertextes. Nous voulons montrer une utilisation éducative de ce moyen avec le but de montrer que l'action de lire se trouve dans un procès d'évolution et qu'il faut s'adapter à la culture digitale.

\section{Mots clés:}

Contenus digitaux; Éducation; Culture; Hypertexte; Video Jeux.

Fecha de recepción: 13-3-2013

Fecha de aceptación: 19-1-2014

\section{Conocimiento y contenidos digitales. Nuevos textos, nuevos lectores}

Sin duda que la irrupción de lo digital en el ámbito social ha supuesto un cambio de costumbres pero su auge implica planteamientos diferentes. Así, ahora se nos plantean las cuestiones referidas a la literatura y 
al conocimiento digital. Tal y como nos relatan Hartley (2007) o Laura Borrás (2010), desconocemos si en el futuro la literatura digital sustituirá a la impresa. Al respecto hay que concretar qué se entiende por literatura digital y en la misma distinguimos la producida por los usuarios de internet (foros específicos, blogs, etc.) y aquella que realizada de manera tradicional usa el medio digital para ser diseminada. Es interesante reflexionar acerca de la primera y es que hay que pensar sobre si la producción que se realiza a través de un blog (por ejemplo escritura creativa o mediante un foro de fans de una obra literaria -aquellos que quieren continuar cuestiones que a su juicio el autor/a autora dejó incompletas) tienen carácter literario. En este sentido planteamos nuestra aportación, retomando las ideas de Gee (2007) o de Webb (2008) quien considera el videojuego como una potencial literatura digital y como un recurso para el acceso al conocimiento y para el desarrollo de la literacidad.

En la línea apuntada por Martos (2006) o Jewit (2008), las ideas que contienen dichos textos (la vanguardia digital propone textos que están barnizados por formatos atractivos y distintos) corresponden al conocimiento por lo que no habría que ser radical y prescindir de los mismos por su naturaleza. El formato narrativo (series de televisión, cómics, videojuegos) mantiene las ideas por lo que no se prescinde de la interpretación de las mismas por parte del receptor. Desde nuestro punto de vista, la diversidad e incluso la posibilidad de plantear escenarios basados en lo leído es positiva. Incluso la posibilidad de tener otros formatos (por ejemplo, la serie de televisión basada en la obra de G.R.R. Martin Canción de hielo y fuego o la de María Dueñas El tiempo entre costuras, puede permitir y animar el acercamiento al libro impreso). Así, en esta línea de pensamiento presentamos la saga Assassin's creed como motivo de acceso al conocimiento, constituyéndose evidentemente en un modo de lectura.

\section{Retóricas de la postmodernidad: el avance de la tecnología}

La referencia que encontramos al encuadrar nuestra propuesta en un tipo de sociedad es el postmodernismo. Es peligroso pensar que la tecnología se puede asociar al poder, pero es una realidad como nos indican Elboj y Puigvert (2002) que mientras la sociología se basa en cuestiones de validez diferentes del poder, el postmodernismo está basado en el poder. 
Textualidad digital y multialfabetización. Los contenidos digitales como material educativo

Amando López Valero e Isabel Jerez Martínez

Dicho planteamiento supone un retroceso en el valor que se le confiere a la lectura ya que en una configuración determinada por la posesión del poder, el acto lector no deja de ser un mero instrumento sobre el que en ocasiones ni siquiera se reflexiona acerca de su presencia y uso. Es más, diversos autores (Lyotard, 1984; Lyon, 1996; Anderson, 2000; Rodríguez Magda, 2004) aludían en su obra a que en un entramado postmoderno no hay universalidad sino que hay singularidad. Este hecho perjudica la consideración de la lectura como una destreza fundamental ya que si no hay acción colectiva definida no es posible conceder valor a la misma por contraste y consenso con el resto de personas.

Así pues, en un contexto en el cual la valoración de la lectura no está clara sí que podemos indicar citando a Albaladejo (2005:33) que

“El prestar atención a todos los discursos, a sus diferentes clases, como una forma de ver no sólo el propio campo de estudio, sino también otros campos, permite mejorar los instrumentos de análisis de cada campo y contribuye a un mejor conocimiento de los objetos de las distintas disciplinas, al enriquecimiento mutuo de éstas y, a la vez, a que cada una de ellas pueda así dar cuenta más completa y adecuadamente de su propio objeto."

Esa diversidad aportada por la era digital supone que la persona tenga a su disposición un mayor número de manifestaciones discursivas. Vásquez (2004) nos indica que en su aspecto operacional las nuevas retóricas ponen en escena diferentes tipos de cruces entre lo real y lo virtual, entre lo sintético y lo natural. De este modo, el procesamiento electrónico de texto representa el cambio más importante en la tecnología de la información desde el desarrollo del libro impreso. Conlleva la promesa (o la amenaza) de producir cambios en nuestra cultura, sobre todo en la literatura, la educación, la crítica y la erudición, al menos tan radicales como los producidos por los tipos móviles de Gutenberg.

Es evidente el cambio producido y la revolución apuntada por Chartier (2000) en la cual hemos transitado del códice al hipertexto. El autor francés incide en que los textos polifónicos, abiertos y móviles, de la textualidad digital pueden interpretarse como una pérdida o una desaparición de las definiciones clásicas de lo que es un libro o una obra.

Los textos individuales dejan de tener fronteras y se reduce la separación jerárquica entre el texto principal y las anotaciones, que ahora existen como textos independientes, unidades de lectura o lexias. Estas 
últimas comprenderán unas veces unas pocas palabras y otras algunas frases: bastará con que sea el mejor espacio posible donde se puedan observar los sentidos; su dimensión, dependerá de la densidad de las connotaciones, que es variable según los momentos del texto. Simplemente se pretende que en cada lexia no haya más de tres o cuatro sentidos que enumerar (Barthes, 1980). Esta situación cambia la perspectiva de autores, lectores y textos. Por consiguiente, los discursos son distintos y el comportamiento de la persona a la hora de leer es distinto. Desde el mundo educativo hay que comenzar a plantear estrategias diferentes para que el proceso de transformación de la lectura no sea traumático y por supuesto para que no se aleje de la interacción con los textos.

\section{Nuevas alfabetizaciones lectoras para un acceso distinto a la cultura}

El entorno cultural ha variado tanto en sus artefactos como en sus manifestaciones. Este hecho provoca una modificación en las acciones de las personas. Una de esas modificaciones tiene que ver con la lectura. Tanto es así que la ley de la lectura del libro y de las bibliotecas (2007), indica que la concepción de la lectura en la actualidad atiende a ser una herramienta básica para el desarrollo de la personalidad y también como instrumento para la socialización. La ciudadanía, a través de numerosos medios y recursos, recibe abundancia de información; mas, en este contexto, es preciso disponer de la habilidad necesaria para transformar la información en conocimientos, y esta capacidad se logra gracias al hábito lector. Ahora bien, ¿la adquisición y mantenimiento de dicho hábito lector es más difícil que antaño debido a la tecnología? La respuesta tiene que ver con la diferencia, no es ni más sencillo ni más complicado. Simplemente es distinta.

Martos (2010) nos indica que la idea originaria de la República de las Letras se configuraba como un ideal ilustrado que pretendía la universalización del conocimiento a través del libre intercambio de ideas entre pensadores y científicos. En estos momentos los recursos tecnológicos nos permiten pensar en la caída de fronteras y la apertura de múltiples posibilidades para el desarrollo de la persona en general y en el ámbito de la lectura en particular.

Ahondando en dicha situación, una de las conclusiones del // Congre- 
Textualidad digital y multialfabetización. Los contenidos digitales como material educativo

Amando López Valero e Isabel Jerez Martínez

so Nacional Leer.es, Leer para aprender. Nuevas Alfabetizaciones, confirmada en las posteriores ediciones, III y IV congreso nacional leer.es, tiene que ver con los objetivos de la alfabetización que se han ampliado para poder incluir las competencias relacionadas con la recepción y la producción de un discurso multimodal. Éste, incluye el lenguaje verbal, los lenguajes audiovisuales y el uso de dispositivos digitales para la composición y la recepción de mensajes. Este conjunto de competencias constituye la alfabetización mediática. Quiere esto decir que la percepción de la lectura como una destreza que se relaciona con una persona ubicada frente a un libro físico ha sufrido una modificación. La virtualidad se fusiona con la realidad y los dispositivos electrónicos complementan la presencia de los físicos.

El modo de estudiar estas narrativas tiene que variar ya que trasciende de su condición de género para tornarse en discurso. Así lo expresa De Fina (2007: 273-274):

"Las narraciones se han convertido en objeto de estudio, tales como: psicología social y del desarrollo, antropología, historia, estudios de género y teoría literaria. Dentro de este marco, la narrativa, al igual que otros géneros discursivos, se considera una práctica discursiva, i.e. un tipo de práctica social basada en el discurso que refleja las creencias y relaciones sociales y a su vez contribuye a negociarlas y modificarlas."

En el citado análisis discursivo, amparado en las manifestaciones sociales que modifican los modos de lectura, hallamos la Inteligencia Artificial Narrativa apuntada por Peinado y Santorum (2004) como automatismos capaces de gestionar la experiencia de acuerdo a convenciones narrativas e interactivas. Dicha inteligencia tiene como objetivo llegar a conseguir una experiencia distinta para cada persona adaptada a sus gustos, sus habilidades y la forma en la que éste interactúa con el texto digital. Finalmente todo se convierte en un modo emergente de lectura ya que se generan inesperados comportamientos mediante las incorporaciones de nuevos elementos y alternativas.

\section{Textualidad digital: el hipertexto}

Inmersos en una cultura denominada digital es preciso definir el con- 
cepto de hipertexto que es el que mejor define el modo de abordar la lectura en la iniciada segunda década del siglo XXI. Podemos considerarlo como un documento electrónico compuesto por unidades textuales interconectadas que forman una red de estructura no lineal. Precisamente en el aspecto no lineal reside el punto esencial del cambio lector. El hecho de tener que leer de un modo distinto puede provocar dispersión y hastío o viceversa, también puede motivar gran satisfacción. De alguna forma, esta situación va a depender del modo de acceder al conocimiento que las personas poseen. Por esa razón, mencionábamos la educación unida a las nuevas situaciones lectoras.

En la línea argumentativa que defendemos en este texto las teorías de Landow (2006) son idóneas para sostener nuestra idea. Así este investigador aboga por el estudio de las reacciones de los usuarios que se convierten en lectores en el espacio digital. Así, su acceso a la llamada biblioteca virtual de las fuentes modifica su modo de lectura. Por ello, se producen diferentes modos de aplicaciones de conectores de información, proliferación de actitudes distintas. En ello, están incluidas todas las formas digitales que se adquieren en el tratamiento de textos (blogs, películas interactivas o videojuegos). Se produce pues un cambio de pensamiento, un cambio en la forma de interactuar con los textos, en definitiva acontece una transformación que afecta a la cotidianeidad de las personas. La textualidad digital transita inexorablemente por el hipertexto y por ello hay que ser conscientes de que en los diseños educativos que se plantean en los diferentes niveles hay que empezar a pensar en la tecnología como algo integrado en cada una de las materias.

Salinas (1994) definía un buen sistema hipertexto como aquel que estimulaba el ojeo y la búsqueda, distintos éstos de la lectura de principio a fin. Realizada la misma tomando como referencia variadas conexiones punto a punto en el entramado de la base de conocimiento. Partiendo de tal concepto aludía al término hipermedia en el cual las mencionadas conexiones llevaban a gráficos, cuadros, secuencias de vídeo o música. Al respecto Fernández Prieto (2001) indicaba que el trabajo con los nuevos software basados en Inteligencia Artificial - denominados como sistemas expertos - que permiten un alto grado de interactividad generada a través del diseño de contextos de aprendizaje interactivo, conllevan el desarrollo de ciertas habilidades mentales, tales como la representación, la asimilación, el aprendizaje a partir de los errores en el momento en que éstos se producen, así como también la aplicabilidad inmediata de 
Textualidad digital y multialfabetización. Los contenidos digitales como material educativo

Amando López Valero e Isabel Jerez Martínez

lo aprendido. Una década después, estas ideas adquieren gran notoriedad ya que los modos de acceder a la información se han transformado.

Leer hipertextos es pues, un hecho constante en nuestro contexto. La persona lectora en la actualidad recibe todo tipo de hipertextos, por lo que es necesario realzar el concepto de interacción e incidir en la formación del lector que se enfrenta cotidianamente a dichos estímulos (Mendoza, 2012). La interacción supone la posibilidad de entender y dar significado a los textos dependiendo de las experiencias que la persona posee. Leer, entonces, significa enfrentarse a un texto no del todo completo o estructurado. El lector, necesariamente activo, participa con todo su bagaje de experiencias propias, su teoría del mundo, sus saberes lingüísticos y su competencia comunicativa, para construir significados a partir de la información que le aporta el texto. Así pues, la situación planteada en estos dos apartados deriva en la necesidad de una nueva alfabetización lectora ya que la cultura ha variado significativamente.

La aparición del hipertexto supone un nuevo cambio histórico y tecnológico que tiene repercusiones culturales puesto que afecta los modos tradicionales de lectura secuencial del texto. El acceso a un hipertexto implica la exploración de contenidos, el lector hace barridos visuales y búsquedas de fragmentos de interés (Nelson, 1992). Se trata de una lectura extensiva, más superficial y horizontal. La inmediatez de contenidos y de información supone una gran ventaja en este tipo de planteamientos, pero a la vez la acumulación de contenidos y, en ocasiones, la evanescencia y no organización adecuada de los mismos supone un hándicap.

El texto que permite que el lector elija, siendo leído en una pantalla interactiva supone una variación significativa y precisa una adecuada alfabetización que debería ser impulsada desde el ámbito educativo (Warschauer, 2000). Finalmente, retomamos la noción referida a que leer es interactuar con el texto y dicha interacción precisa de una adaptación a los nuevos formatos. Así, la lectura en medio electrónico es un proceso de construcción de conocimiento a partir de varias fuentes interconectadas por medio de los hipervínculos. En este caso, la lectura exige nuevas habilidades, como identificar las informaciones que deben ser leídas primero o decidir si leer o no una página abierta. La apertura del hipertexto frente al texto lineal permite que el lector pueda llegar a diferentes caminos. Al contrario de lo que se pueda pensar los textos digitales o electrónicos tienen su estructura y organización, la diferencia 
estriba en que no se ordenan secuencialmente como los textos físicos.

Finalmente todo se convierte en un modo emergente de lectura ya que se generan inesperados comportamientos mediante las incorporaciones de nuevos elementos y alternativas. En el siguiente apartado nos centraremos en el videojuego como contenido digital que puede alcanzar el grado de lectura y lo haremos mediante el análisis de una de las compañías que trabaja de un modo más acertado con los conceptos de hipermedia e hipertexto. Optar por esta situación viene motivado por la conductas sociocomunicativas de los residentes digitales (García y Rosado, 2012) y porque la utilización de videojuegos supone una de las señas de identidad de la juventud que forma parte del siglo XXI (García y otros, 2011).

\section{Contenidos digitales y multialfabetización: los videojuegos}

Somos parte de la denominada cultura digital y esta situación condiciona nuestra cotidianeidad. Podríamos indicar que la misma se corresponde con el conjunto de producciones artísticas y culturales realizadas mediante componentes electrónicos u ordenadores. Ésta podría ser una definición simple que podría caracterizar nuestra sociedad. Nos interesa en esta aportación abordar los contenidos digitales como seña de identidad de la mencionada sociedad. Los mismos, en forma de textos digitales, páginas webs, e-books, suponen una revolución que afecta al conocimiento (a su aprehensión y entendimiento). Por esa razón, en este apartado prestaremos especial atención a los contenidos digitales y dentro de los mismos a los videojuegos. La proliferación de estudios académicos concretos dedicados a los mismos, como por ejemplo la aportación coordinada por Marín Díaz (2012) justifica esta sección.

El Informe Anual de los Contenidos Digitales en España (2011) nos proporciona información significativa y relevante acerca de los videojuegos. Y es que más allá de ser un elemento que originariamente se centraba en el entretenimiento, su auge y emergencia social provoca que tenga que ser motivo de estudio sobre todo para observar su incidencia en los niveles educativos que tienen que ver principalmente con la Educación Primaria y Secundaria. Debemos ser conscientes de que el sector de los videojuegos está evolucionando de manera muy notable gracias al desarrollo de la tecnología y de las redes de banda ancha, descubriendo 
Textualidad digital y multialfabetización. Los contenidos digitales como material educativo

Amando López Valero e Isabel Jerez Martínez

nuevos modelos de negocio on-line. De igual manera, el citado informe nos indica que los videojuegos están siendo utilizados como herramienta de marketing alternativa a los medios tradicionales, teniendo, para un mismo coste, mayor impacto sobre los usuarios. Además de que los videojuegos están siendo utilizados por otros sectores como la medicina, la educación o la defensa para el desarrollo de su actividad.

Lacasa (2011: 20) retoma la definición del antropólogo holandés Johan Huizinga y aplica la misma en juegos reales y en virtuales:

"El juego es una actividad libre y consciente, que ocurre fuera de la vida "ordinaria" porque se considera que no es seria, aunque a veces absorbe al jugador intensa y completamente. Es ajena a intereses materiales y de ella no se obtiene provecho económico. Esa actividad se realiza de acuerdo con reglas fijas y de una forma ordenada, dentro de unos determinados límites espacio-temporales. Promueve la formación de grupos sociales que tienden a rodearse a sí mismos de secretos y a acentuar sus diferencias respecto del resto utilizando los medios más variados"

Los videojuegos se caracterizan por una fuerte capacidad de retroalimentación. Este es otro de los aspectos que hace tan atractivo y tan difícil de abandonar ese mundo de ficción. El número de recompensas, y logros es parte de la nueva narrativa ficcional (sin duda que podemos apreciar este hecho como una transposición del sistema económico que subyace al funcionamiento social). El usuario se convierte en parte activa de los mismos. El concepto de ficción interactiva supone que su aplicación sea variada, sobre todo debido a la diversidad morfológica. Así, habrá variaciones dependiendo del autor y del contenido de la obra. Sin embargo, sí podemos indicar cuestiones comunes como, por ejemplo, la interactividad. La misma supone una transformación radical en la forma de recepción de la ficción, la persona lectora se convierte en protagonista en ocasiones, o autora en otras, gracias a la interactividad. La experiencia de recepción se hace más rica y plural, más profunda y completa.

La posibilidad de elección de diferentes posibilidades de continuación de la narración, elección de nuevas secuencias de la misma, y también de nuevos caminos de información es planteada por Esnaola y Levis (2008) como un avance cultural. Es más, cada vez se reúnen una mayor cantidad de profesionales que consideran posible el desarrollo, producción y difusión de productos mediáticos - y en particular videojuegos- 
valiosos culturalmente. Por eso, estos autores propugnan un encuentro interdisciplinar entre el ámbito educativo y la industria de la comunicación. El formato cambia pero la forma de acceder al conocimiento y a los contenidos tiene que ver con la lectura. Buscamos pues en este texto una actualización de contenidos, una búsqueda de recursos válidos que permitan a la persona seguir aprendiendo pero de forma contextualizada y acorde con los tiempos en los cuales vive.

Lacasa (2011:54) incide en la trascendencia educativa de los videojuegos de este modo:

"Creo que son una buena escuela para aprender a crear. Hoy, en una sociedad que exige no sólo recibir mensajes sino también producirlos, enfrentar a los estudiantes a expresarse utilizando algunos de los principios presentes en su diseño puede contribuir a crear escenarios educativos innovadores relacionados con nuevas formas de alfabetización"

Así pues, en la siguiente sección pretendemos adentrarnos en posibilidades educativas de la saga Assassin's creed, comprobando que en sus contenidos hay potencial para que los usuarios accedan al conocimiento cultural. Queremos mostrar las posibilidades relativas a la multialfabetización que nos ofrece ya que múltiples dimensiones políticas, culturales y académicas se incluyen en el mismo.

\section{Propuesta educativa basada en la saga Assassin's creed}

La desmitificación relativa a los videojuegos comienza a ser algo evidente. El hecho de desterrar asunciones como los videojuegos son una pérdida de tiempo y además, son violentos, se está produciendo. La clave reside en el modo de uso de los mismos. Al respecto Gee (2007) resalta varias cuestiones altamente relevantes y que se sitúan en la vanguardia de la investigación concerniente al tema. Así, cómo utilizamos los videojuegos para adquirir un sentido de identidad; cómo construimos la interpretación del videojuego; cómo el usuario valora y ejecuta las acciones mientras juega; cómo el usuario elige un modelo de comportamiento; y, sobre todo, cómo se percibe el mundo y la realidad, se convierten en preguntas clave para aclarar determinados patrones de comportamiento de pensamiento de las generaciones que pueblan el planeta. 
Textualidad digital y multialfabetización. Los contenidos digitales como material educativo

Amando López Valero e Isabel Jerez Martínez

Por ello, consideramos que la explotación educativa de los potentes videojuegos que actualmente se distribuyen socialmente es motivo de estudio y debe convertirse en una significativa aportación al ámbito social y educativo. De acuerdo con Prensky (2011), debemos aprovechar la especialización de los estudiantes como buscadores de información y presentación de contenidos a través de la tecnología. El docente guiará a dicho alumnado proporcionándoles preguntas y contextos. El caso que nos ocupa tiene que ver con la saga Assassins's creed. Dichos videojuegos han sido ampliamente galardonados y su trama se sitúa en torno a una secta conocida como la Orden Secreta de Hashshashin (Asesinos). La alusión literaria al mismo corresponde a la recuperación de las historias referidas a los templarios y sus misiones en el contexto de las cruzadas. Varias ediciones convierten a este videojuego en una saga. Así, Assassin's Creed II supone la continuación del primer juego. La secuela de Assassin's Creed II, Assassin's Creed: Brotherhood, es lanzada al mercado en noviembre de 2010, un año después se pone a la venta Assassin's Creed: Revelations, Assassin's Creed III, año 2012; y la última entrega es Assassin's Creed IV: Black Flag en el año 2013.

Desde el punto de vista de su utilización didáctica el videojuego escogido reúne los criterios de funcionalidad apuntados por Moreno Herrero (1996), tales como: ser una herramienta de apoyo o ayuda para nuestro aprendizaje, siendo útiles y funcionales. Y, sobre todo, no aspiran a sustituir al profesorado en su tarea de enseñar $y$, desde una perspectiva crítica, permite que el aprendizaje sea construido entre todas las personas implicadas en el proceso de aprendizaje.

El videojuego incluye grandes ciudades y lugares de la Edad Media, como el castillo de Masyaf, Damasco, San Juan de Acre y Jerusalén. Posteriormente, en las dos últimas ediciones, la trama tiene lugar principalmente en Roma (Brotherhood) y en Estambul (Revelations). Es en éstas últimas en las que vamos a centrar nuestra propuesta educativa, ya que consideramos ambas ubicaciones claves para entender la difícil relación que históricamente se ha mantenido entre oriente y occidente. Por ello, pensamos que el caudal del conocimiento que se puede extraer por parte del usuario jugando a Assassin's Creed: Brotherhood es relevante. Pensemos que los lugares perfectamente descritos y reproducidos en el juego: Tívoli, Puerta Aureliana, Basílica de San Pedro, Termas de Diocleciano, Castillo de San Angelo, Plaza de España, San Giovanni de Florencia, Arco de Constantino, Plaza Navona, Columna de Trajano, Monte 
Palatino, Circo Máximo, Coliseo, Arco de Tito, Capilla Sixtina, Palacio del Senado, Capitolio, Panteón, suponen el conocimiento de una de las ciudades más relevantes de nuestra historia más cercana. Cualquiera de estas ubicaciones puede ser objeto de reflexión por parte de un educador, y es que un buen mediador entre este videojuego y el usuario puede lograr que parte de la cultura pueda ser adquirida de forma lúdica. El hecho de que estos lugares sean clave para la resolución del juego implica que el educador pueda valerse del videojuego para explicar esos lugares y su trascendencia para nuestra historia y cultura. Sucede algo similar con los personajes, ya que personas con relevancia histórica aparecen en la trama: César Borgia, Rodrigo Borgia, Leonardo Da Vinci, Nicolás de Maquiavelo, Lucrecia Borgia. Pensemos que Maquiavelo puede conducirnos a sus tratados literarios y de igual modo, el genio Leonardo nos acercará a muchas de sus manifestaciones (pintura, arquitectura, inventos, etc.).

En el caso de Assassin's creed revelations, la acción situada en Constantinopla nos ofrece la posibilidad de conocer los lugares importantes de este enclave relevante en la historia. Así, el Obelisco de Teodosio, Torre de la doncella, Columna de Marciano, Foro de Teodosio, Santa Irene, Foro de Constantino, Acueducto de Valente, Foro del Buey, Pequeña Santa Sofía, Gran Bazar, Mezquita de la Rosa, Palacio de Topkapi, Santa Sofía, Torre del Gálata, Cuerno de Oro, son lugares que se describen y observan durante la acción del juego. Al igual que ocurría con su precedente, personajes y sobre todo, colectivos, son descritos en la trama. Por ello, es posible para el educador trabajar con los conceptos referidos a quiénes eran los jenízaros, los otomanos, los bizantinos e incluso los gitanos. Los flashback constantes nos permiten acceder a información y hechos históricos relacionados con la Edad Media.

En la penúltima de las entregas publicadas, Assassin's Creed III, el usuario tiene que adoptar la personalidad de Connor Kenway, un asesino que ha prometido liberar a su pueblo y nación. La historia transcurre en Estados Unidos y se ambienta en la guerra de la independencia, permitiendo en este caso al usuario conocer aspectos de una época de la historia y un acercamiento al mencionado acontecimiento. Por lo que esta tercera edición del producto también contribuye a poner a disposición social un material que, si bien divierte, igualmente puede constituirse como un recurso educativo. La última entrega es una precuela de esta, por lo que sus posibilidades educativas serían semejantes. 
Textualidad digital y multialfabetización. Los contenidos digitales como material educativo

Amando López Valero e Isabel Jerez Martínez

Así pues, nuestra reivindicación educativa con respecto de esta saga, reside en el amplio acervo de conocimientos que la misma encierra y que sin duda son tratados por el usuario del videojuego. Desde nuestro punto de vista, el educador/mediador puede rescatar este contacto para poder incidir en la reflexión sobre lugares, personajes y de igual modo, puede ahondar en el conocimiento de las culturas y establecer un proceso reflexivo tendente a comprender que la conciliación y el respeto por lo occidental o por lo oriental es importante. De este modo, el videojuego se convierte en un potente recurso de acceso al conocimiento. Recordemos que en la cultura digital no todo depende de la influencia social, es más, algo tiene que decir el ámbito educativo ya que si bien la sociedad dota de los artefactos y de la tecnología a las personas, la inmanencia no es la mejor opción para comprender y saber usar adecuadamente los mismos (Pérez Tapias, 2006). Por esta razón, no es tan lejano el momento en el cual el planteamiento del currículum varíe y se adapte a estas transformaciones sociales que sin duda condicionan el modo de aprehender la realidad.

\section{Conclusiones. Las formas de acceso al conocimiento han evolucionado}

Atendiendo a estos datos, hemos centrado nuestra aportación en la búsqueda de la relación entre la lectura, el acceso al conocimiento y los videojuegos. Nuestra elección ha sido específica ya que deseábamos mostrar un recurso que facilitase al educador nuevas posibilidades. Al respecto, existen desarrolladores de videojuegos que en su concepción de estos objetos textuales perfilan dimensiones relacionadas con la textualidad digital, es decir se incluyen cuestiones que incitan y reclaman del usuario cualidades lectoras y conocimientos previos que deben ser adquiridos mediante el acto lector, y éste es el caso de la saga Assasin's creed.

En la línea aportada por Anstey y Bull (2007) se promulga el incentivar las alfabetizaciones múltiples. Esto es, ofrecer principios que guíen el desarrollo de un currículo multialfabetizador. También conocidas como multiliteracidades, éstas se centran en la manera en que la alfabetización y las prácticas de lectura y escritura reciben la influencia de cambios mundiales, locales, culturales y tecnológicos. Una pedagogía orientada 
a las alfabetizaciones múltiples implica la enseñanza de un espectro variado de habilidades: de pensamiento, de conducta y habilidades sociales. Hemos visto que la saga por nosotros escogida, aparte de incidir en otros aspectos, trata de manera específica la dimensión intercultural mostrándonos partes de la historia, personajes, ciudades y civilizaciones. A esto hay que añadir la parte de ficción que entronca con el aspecto narrativo y la labor lectora que desempeña el usuario.

Para poder llevar a cabo dicha propuesta de currículum hay que estar abierto a la utilización de todo tipo de recursos, partiendo de la premisa del valor académico que puedan tener y no de la consideración o estereotipo que se les pueda atribuir. Por ello, pensamos que los videojuegos pueden tener un aprovechamiento educativo, como hemos mencionado previamente, por ejemplo, en la promoción de la lectura.

Es evidente que los textos digitales en sus diferentes manifestaciones son una realidad y un recurso educativo a disposición de los educadores. Por ello, familiarizarse con los mismos o tener un conocimiento sobre ellos es fundamental para tener nuevas vías de acceso para la motivación de los estudiantes en la búsqueda del acceso de los mismos al conocimiento cultural. Una industria tan potente como es la del videojuego no debería ser desaprovechada por el mundo educativo. Desterrando los falsos estereotipos deberíamos de darnos cuenta de que determinadas producciones pueden ser tratadas desde un punto de vista estético y funcional como obras artísticas con las que también se puede aprender.

\section{Referencias bibliográficas}

Albaladejo, T. (2005). Retórica, comunicación, interdiscursividad. Revista de investigación lingüística, vol VIII, 7-33.

Anderson, P. (2000). Los orígenes de la posmodernidad. Madrid: Anagrama.

Anstey, M. y Bull, G. (2007). Principios básicos de un currículo centrado en alfabetizaciones múltiples. Lectura y vida: revista latinoamericana de lectura, 2, 56-62.

Barthes, R. (1980). Mitologías. Madrid: Siglo XXI.

Borrás, L. (2010). Nuevos lectores. Nuevos modos de lectura en la era digital. En S. Montesa (Ed.). Literatura e internet. Nuevos textos, nuevos lectores. Málaga: AEDILE, 41-66.

Chartier, R. (2000). Las revoluciones de la cultura escrita. Diálogo e intervenciones. Barcelona: Gedisa.

De Fina, A. (2007). Cruzando fronteras: tiempo, espacio y desorientación en la narrativa. Discurso \& Sociedad, Vol 1(2), 270-294. 
Textualidad digital y multialfabetización. Los contenidos digitales como material educativo

Amando López Valero e Isabel Jerez Martínez

Elboj, C. y Puigvert, L. (2002). No se puede hacer sociología desde la postmodernidad: diferencias entre la perspectiva postmoderna y sociológica. Acciones e investigaciones sociales, 14, 253-267.

Esnaola, G. y Levis, D. (2008). Educación y cultura en la sociedad de la información. Revista electrónica de teoría de la educación, 9 (3). Consultado el 28/06/2010 en http:// www.usal.es/teoriaeducacion

Fernández, M. (2001). Hacia alternativas para el aprendizaje con programas hipermedia. Pixel-Bit: revista de medios y educación, 16. Consultado el 28/12/2010 en http:// www.sav.us.es/pixelbit/pixelbit/articulos/n16/n16art/art164.htm

García García, F., Durán, J. F., Gértrudix, F., Gamonal, R. y Gálvez, Mª C. (2011). Señas de identidad del "nativo digital". Una aproximación teórica para conocer las claves de su unicidad. Cuadernos de documentación multimedia, 22, 110-127.

García García, F. y Rosado, Mª J. (2012). Conductas sociocomunicativas de los nativos digitales y los jóvenes en la Web 2.0. Comunicación y sociedad: Revista de la Facultad de Comunicación, 22, 15-38.

Gee, J. P. (2007). What video games have to teach us about learning and literacy. New York: Palgrave MacMillan.

Hartley, J. (2007). Teaching, learning and new technology: a review for teachers. British Journal of Educational Technology, 38 (1), 42-62.

Jewit, C. (2008). Technology, Literacy and Learning: A Multimodal Approach. London: Routledge.

II congreso leer.es. (2010) Conclusiones. Consultado el 28/12/2010 en http://leer.es/iicongreso-nacional-leeres-leer-para-aprender-nuevas-alfabetizaciones/

Informe Anual de los Contenidos Digitales en España 2010. Madrid: Equipos de Estudios e Indicadores del ONTSI, con el asesoramiento y colaboración de Neoris.

Lacasa, P. (2011). Los videojuegos. Aprender en mundos reales y virtuales. Madrid: Morata.

Landow, G. P. (2006). Hypertext 3.0: critical theory and new media in an era of globalization. Baltimore: John Hopkins university press.

Ley 10/2007, de 22 de junio, de la lectura, del libro y de las bibliotecas. BOE 23 junio 2007.

Lyon, D. (1996). Postmodernidad. Madrid: Alianza.

Lyotard, F. J. (1984). La condición postmoderna. Madrid: Siglo XXI.

Marín Díaz, V. (Coord.) (2012). Los videojuegos y los juegos digitales como materiales educativos. Madrid: Síntesis.

Martos, E. (2006). "Tunear" los libros: series, fanfiction, blogs y otras prácticas emergentes de lectura. Ocnos, 2, 63-77.

Martos, E. (2010). De la República de las Letras a Internet: de la Ciudad Letrada a la cibercultura y las tecnologías del S. XXI, Álabe, 1, Consultado el 28/12/2010 en http:// nevada.ual.es:81/aalabe/index.php/alabe/article/view/10

Mendoza, A. (2012). (Coord.). Leer hipertextos. Del marco hipertextual a la formación del lector literario. Barcelona: Octaedro.

Moreno, I. (1996). Las nuevas tecnologías como nuevos materiales curriculares. Educación y Medios, 2, 40-47. 
Textualidad digital y multialfabetización. Los contenidos digitales como material

educativo

Amando López Valero e Isabel Jerez Martínez

Nelson, T. (1992). Literary machines. Sausalito CA: Mindful Press.

Peinado, F. y Santorum, M. (2004). Juego Emergente: ¿Nuevas formas de contar historias en videojuegos?, Icono14, 4. Consultado el 28/12/2010 en www.icono14.net/revista/ num $4 /$ michael.doc

Pérez Tapias, J. A. (2006). Tareas de la educación en la cultura digital. Educere: revista venezolana de educación, 32, 17-26.

Prensky, M. (2011). Enseñar a nativos digitales. Madrid: SM.

Rodríguez Magda, R. Ma . (2004). Transmodernidad. Barcelona: Anthropos.

Salinas, J. (1994). Hipertexto e hipermedia en la enseñanza universitaria. Pixel-Bit: revista de medios y educación, 1. Consultado el 28/12/2010 en http://www.sav.us.es/pixelbit/pixelbit/articulos/n1/n1art/art12.htm

Vásquez, A. (2004). El hipertexto y las nuevas retóricas de la postmodernidad. Philosophica, 27, 331-350.

Warschauer, M. (1997). Computer-mediated collaborative learning: theory and practice. Modern language journal, 81 (4), 470-481

Webb, N. (2008). Persuasive games: the expressive power of videogames. British Journal of Educational Technology, 39 (5), 951.

\section{Página Web:}

http://assassinscreed.es.ubi.com 
